\title{
Alterações bucais e sistêmicas da Histiocitose de Células de Langerhans em paciente pediátrico: Relato de caso
}

\author{
Oral and systemic changes in Langerhans Cell Histiocytosis in a pediatric patient: Case report \\ Cambios orales y sistémicos em la histiocitosis de células de Langerhans em um paciente pediátrico:
}

Reporte de caso

Recebido: 30/03/2021 | Revisado: 08/04/2021 | Aceito: 09/04/2021 | Publicado: 18/04/2021

\author{
Chauí de Lima Cabral \\ ORCID: https://orcid.org/0000-0002-0931-4706 \\ Universidade Potiguar, Brasil \\ E-mail: chaui786@gmail.com \\ Nayron Lourenço Ivo de Souza \\ ORCID: https://orcid.org/0000-0002-8749-7464 \\ Universidade Potiguar, Brasil \\ E-mail: nayronlourenco23@gmail.com \\ Romário Dias da Cunha \\ ORCID: https://orcid.org/0000-0002-3077-6665 \\ Universidade Potiguar, Brasil \\ E-mail: romariodiasc@gmail.com \\ Ana Larissa Fernandes de Holanda Soares \\ ORCID: https://orcid.org/0000-0002-3740-7862 \\ Universidade Potiguar, Brasil \\ E-mail: professoralarissaunp@gmail.com
}

\begin{abstract}
Resumo
A Histiocitose de Células de Langerhans $(\mathrm{LCH})$ é uma desordem associada à proliferação das células de Langerhans. Devido à sua natureza infiltrativa, a LCH pode envolver órgãos como a pele, os gânglios, o pulmão e o fígado. Estima-se que sua incidência é de aproximadamente 5 a 10 casos em um milhão por ano, principalmente em menores de 15 anos, com predominância no sexo masculino, na proporção de 2:1 e sua patogênese permanece desconhecida. Objetivou-se com este estudo descrever as manifestações sistêmicas e orais da LCH, em uma criança, destacando a importância do cirurgião-dentista no diagnóstico precoce das lesões bucais na atenção básica. Para descrição do caso clínico, as informações foram obtidas por meio de consulta ao prontuário do paciente no Hospital Universitário Onofre Lopes - HUOL. Paciente do sexo masculino, 4 meses, apresentava lesões na cavidade oral em rebordo alveolar inferior, superior e palato duro, exofíticas formada por regiões eritroplásicas e leucoplásicas não removida durante raspagem, com distensão abdominal, fontanela normotensa, presença de "nódulo" cefálico parietal, ictérico, colúria, hipocolia fecal e genitália hiperemiada. Concluímos que a criança possuía quadro clínico compatível com LCH. Este trabalho mostrou ainda a importância do cirurgião-dentista, especialmente na Atenção Básica de saúde, para o correto diagnóstico de doenças sistêmicas, com manifestações bucais, assim como a sua responsabilidade na ordenação do cuidado na busca pela integralidade da atenção.
\end{abstract}

Palavras-chave: Histiocitose de células de Langerhans; Crianças; Patologia bucal; Odontopediatria.

\begin{abstract}
Langerhans Cell Histiocytosis (LCH) is a disorder associated with the proliferation of Langerhans cells. Due to its infiltrative nature, $\mathrm{LCH}$ can involve organs such as the skin, the ganglia, the lung and the liver. It is estimated that its incidence is approximately 5 to 10 cases in a million per year, mainly in children under 15 years old, with a predominance in males, in the proportion of 2: 1 and its pathogenesis remains unknown. The objective of this study was to describe the systemic and oral manifestations of $\mathrm{LCH}$ in a child, highlighting the importance of the dental surgeon in the early diagnosis of oral lesions in primary care. For the description of the clinical case, the information was obtained by consulting the patient's medical record at Hospital University Onofre Lopes - HUOL. Male patient, 4 months old, presented lesions in the oral cavity in the lower, upper alveolar ridge and hard palate, exophytic formed by erythroplastic and leukoplastic regions not removed during scraping, with abdominal distension, normotensive fontanelle, presence of parietal cephalic "nodule", jaundice, choluria, fecal hypocholia and hyperemic genitals. We concluded that the child had a clinical condition compatible with LCH. This work also showed the importance of the dentist, especially in Primary Health Care, for the correct diagnosis of systemic diseases, with oral manifestations, as well as his responsibility in ordering care in the search for comprehensive care.
\end{abstract}


Keywords: Langerhans cell histiocytosis; Children; Oral pathology; Pediatric dentistry.

\section{Resumen}

La histiocitosis de células de Langerhans ( $\mathrm{LCH})$ es un trastorno asociado con la proliferación de células de Langerhans. Debido a su naturaleza infiltrativa, la LCH puede afectar órganos como la piel, los ganglios, el pulmón y el hígado. Se estima que su incidencia es aproximadamente de 5 a 10 casos en un millón por año, principalmente en menores de 15 años, con predominio en el sexo masculino, en la proporción de 2: 1 y su patogenia permanece desconocida. El objetivo de este estudio fue describir las manifestaciones sistémicas y bucales de la LCH en un niño, destacando la importancia del cirujano dentista en el diagnóstico precoz de las lesiones bucales en atención primaria. Para la descripción del caso clínico, la información se obtuvo consultando la historia clínica del paciente en el Hospital Universitário Onofre Lopes - HUOL. Paciente masculino de 4 meses de edad que presenta lesiones en cavidad oral en reborde alveolar superior e inferior y paladar duro, exofíticas formadas por regiones eritroplásicas y leucoplásicas no removidas durante el raspado, con distensión abdominal, fontanela normotensa, presencia de "nódulo" cefálico parietal , ictericia, coluria, hipocolía fecal y genitales hiperémicos. Concluimos que el niño presentaba un cuadro clínico compatible con LCH. Este trabajo también mostró la importancia del odontólogo, especialmente en Atención Primaria de Salud, para el correcto diagnóstico de las enfermedades sistémicas, con manifestaciones bucales, así como su responsabilidad en la ordenación de la atención en la búsqueda de una atención integral.

Palabras clave: Histiocitosis de células de Langerhans; Niños; Patología bucal; Odontología pediatrica.

\section{Introduçãa}

O complexo de doença anteriormente conhecido como Histiocitose X, é uma designação coletiva para um espectro de doenças clinicopatológicas, caracterizadas pela proliferação de células semelhantes a histiócitos, que são acompanhadas por números variáveis de eosinófilos, linfócitos, plasmócitos e células gigantes multinucleadas. Estas células histiocíticas distintas presentes nessa lesão foram identificadas como células de Langerhans, e a condição é agora designada como Histiocitose de Células de Langerhans (LCH) (Neville, 2016).

Estima-se que sua incidência é de aproximadamente 5 a 10 casos em um milhão por ano, principalmente em menores de 15 anos. Predomina no sexo masculino, na proporção de 2:1 (Aricó, et al., 2003). A patogênese permanece desconhecida. Sua natureza reacional ou neoplásica ainda é debatida, embora existam mais argumentos a favor da primeira opção (Savasan, 2006).

Por seu envolvimento multissistêmico, a LCH pode se apresentar de várias maneiras, e devido à sua natureza infiltrativa, pode envolver a pele, os gânglios, o pulmão ou o fígado (Kapoor, et al., 2015). São doenças raras de grande variabilidade biológica e uma ampla gama de manifestações clínicas (Schmidt, et al., 2004).

Em manifestação na cavidade oral pode ser a mais cedo ou mesmo o único sintoma de LCH (Anniballi, et al., 2009). E ao mesmo tempo, os sintomas orais da doença é a mais frequente, já que aparecem em 77\% de todos casos. Na mucosa oral e nos tecidos periodontais, as erosões ovoides ou ulcerações com margens eritematosas tumorais aparecem, seguido de dor durante palpação e afrouxamento dos dentes (Fistarol, et al., 2009). As lesões bucais podem indicar o início ou evolução de alguma enfermidade, e, portanto, podem funcionar como um sistema de alarme precoce para algumas doenças (Ribeiro, et al., 2012).

Diante do exposto, o presente trabalho objetivou descrever as manifestações sistêmicas e orais da LCH, em uma criança.

\section{Metodologia}

Trata-se de um estudo de caso clínico, realizado na Unidade Básica de Saúde de Serrinha - São Gonçalo do Amarante - RN e no Hospital Universitário Onofre Lopes. No primeiro momento, foi realizado o contato com a mãe do paciente, moradora do município de São Gonçalo do Amarante/RN, para apresentação do projeto e solicitação de autorização. Para a 
caracterização e descrição do caso clínico, foi realizada consulta aos prontuários do paciente. Dois pesquisadores apenas tiveram acesso ao prontuário e foram anotados os dados relevantes para a descrição da patologia. Além do prontuário hospitalar do paciente (Hospital Universitário Onofre Lopes), para o melhor entendimento da síndrome, foram coletados dados do prontuário clínico na Unidade Básica de Saúde de Serrinha, na qual ocorreu o primeiro acolhimento da criança.

O presente trabalho foi aprovado pelo Comitê de Pesquisa do Hospital Universitário Onofre Lopes (HUOL) e da Universidade Potiguar (UnP), sob o número 2.471.520. A autorização para participar do estudo, por meio de termo de consentimento, foi obtida após os pais serem informados das razões do estudo, deixando claro que os dados seriam mantidos em sigilo e a identidade da criança resguardada. Toda pesquisa com seres humanos envolve risco em tipos e gradações variados. Este trabalho apresentou o risco de possível exposição do prontuário clínico do paciente. Esse risco foi minimizado por meio de consultas ao prontuário em local reservado.

Este trabalho teve como importante benefício um maior conhecimento sobre a associação entre lesões bucais e a Histiocitose de Células de Langerhans. Além disso, contribuiu para um melhor esclarecimento a respeito das alterações sistêmicas dessa síndrome e sua evolução e favoreceu uma discussão sobre a necessidade de um diagnóstico precoce, a importância do olhar clínico do cirurgião-dentista para o seu reconhecimento e a necessidade da inserção desse profissional em uma equipe multiprofissional.

\section{Relato de Caso}

Paciente do sexo masculino, 4 meses compareceu a Unidade Básica de Saúde da comunidade de Serrinha - São Gonçalo do Amarante - RN, para consulta odontológica acompanhado pela mãe. Durante o exame clínico, foram identificadas lesões na cavidade oral em rebordo alveolar inferior, superior e palato duro, exofíticas formada por regiões eritroplásicas e leucoplásica não removida durante raspagem (Figuras 1 e 2). No primeiro momento, e com base na anamnese realizada, a hipóteses diagnóstica foi de Cisto de erupção, tanto pelo aspecto clínico, como pelo período coincidente com a cronologia de erupção da dentição decídua.

Figura 1. Lesões em rebordo alveolar superior.

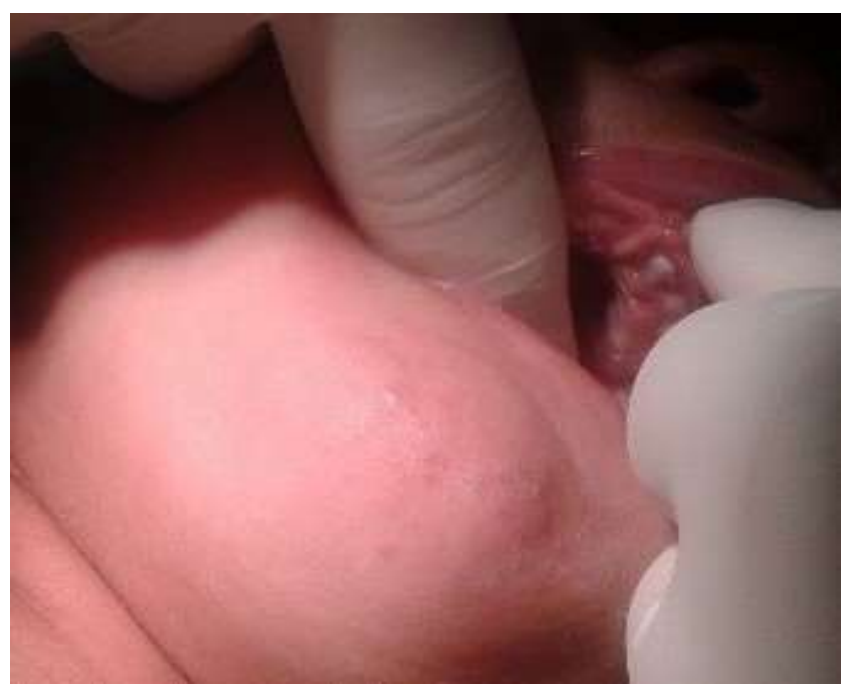

Fonte: Autores. 
Figura 2. Lesões em rebordo alveolar inferior.

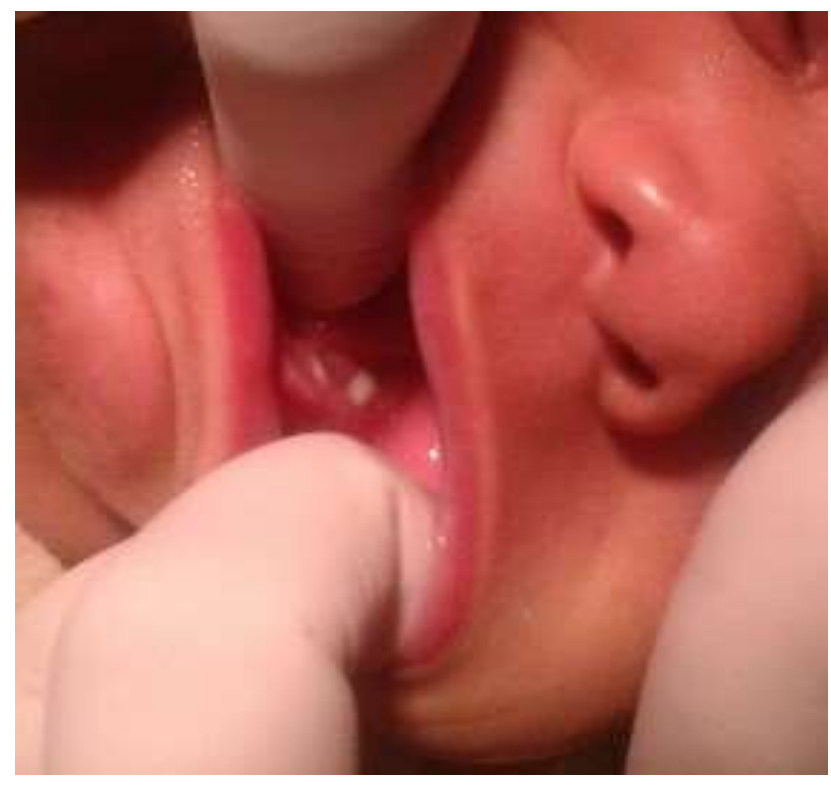

Fonte: Autores.

O paciente foi encaminhado ao setor de patologia da Universidade Federal do Rio Grande do Norte (UFRN), o qual posteriormente solicitou avaliação do pediatra, uma vez que foram identificadas manchas azuladas no corpo da criança (Figuras 3 e 4). De acordo com o exame clínico, realizado pelo especialista na Unidade Básica de Saúde, as lesões foram diagnosticadas como manchas mongólicas, as quais são benignas e estão ligadas a descendência genética da criança. As manchas são comuns em bebês que têm como antepassados asiáticos, indígenas, hispânicos e/ou africanos.

Figura 3. Manchas azuladas em dorso superior posterior.

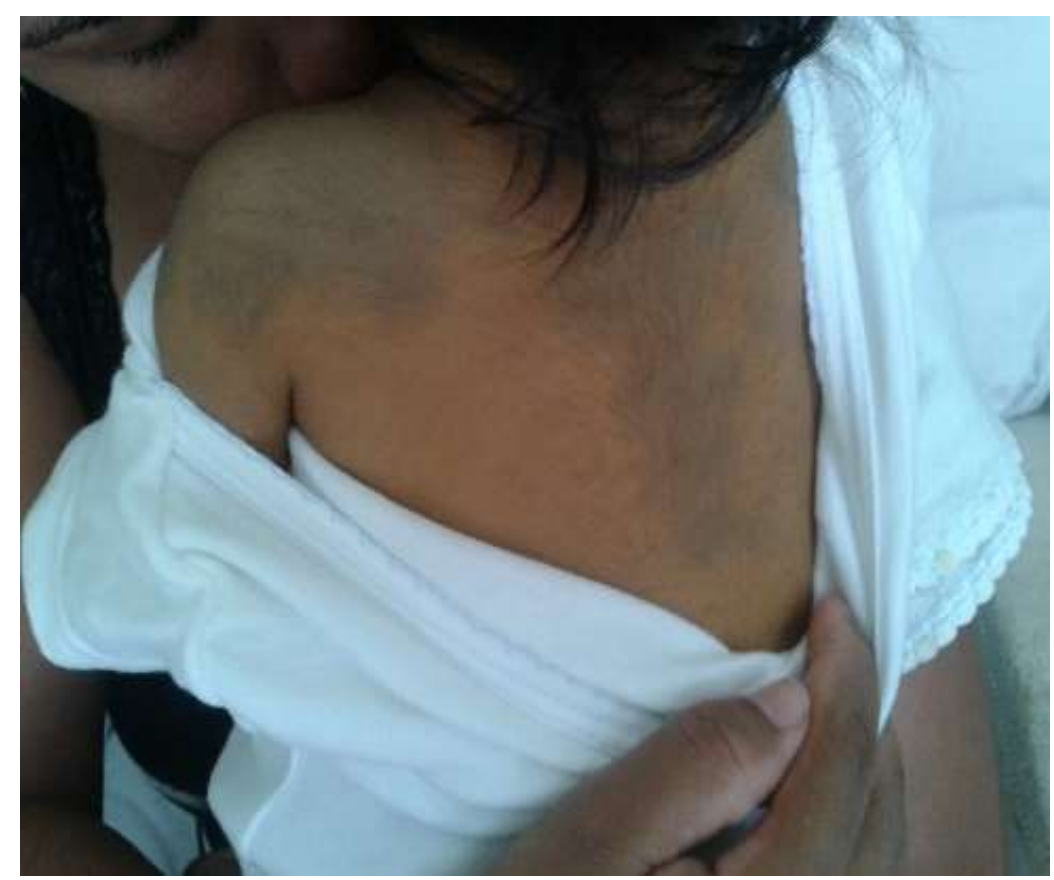

Fonte: Autores. 
Figura 4. Manchas azuladas em membro inferior.

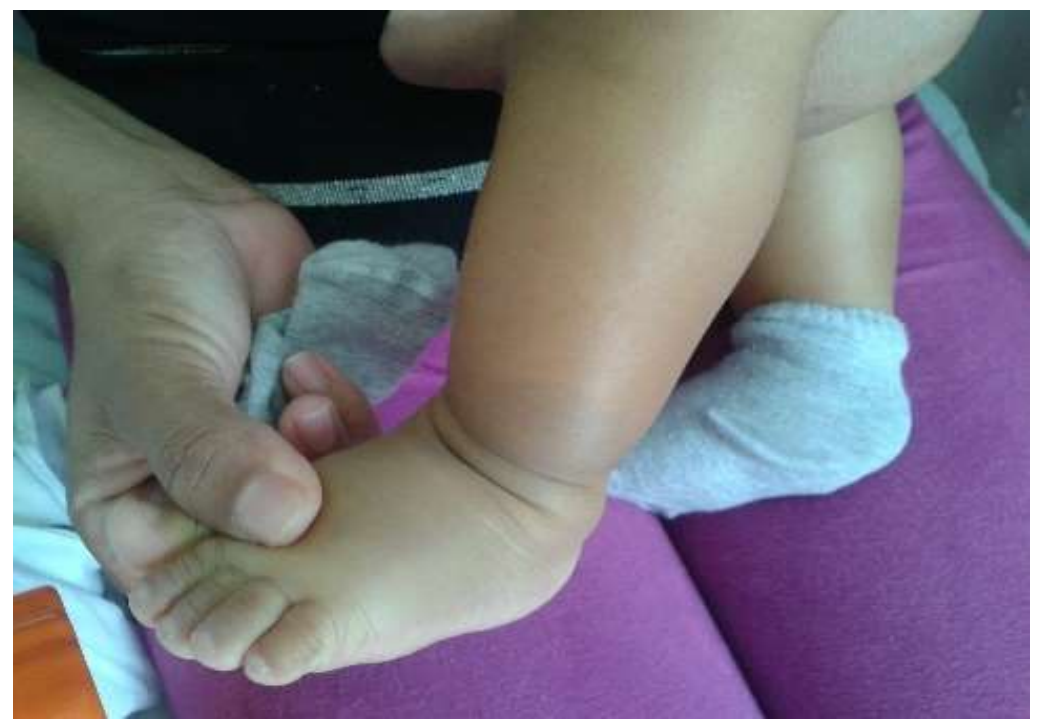

Fonte: Autores.

A mãe foi orientada a retornar ao setor de patologia da UFRN, mas, nesse intervalo de tempo, o paciente apresentou piora no quadro clínico, com distensão abdominal e icterícia e precisou ser transferido para ambulatório do Hospital de Pediatria da UFRN (HOSPED), conforme Figura 5.

Figura 5. Distensão abdominal e ictérico.

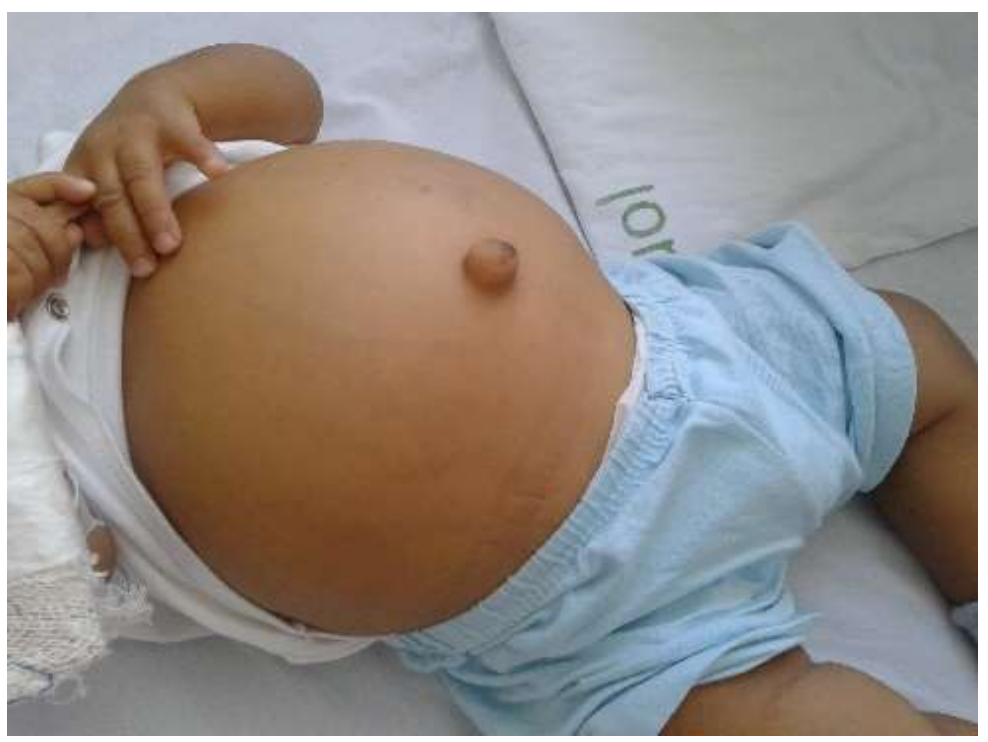

Fonte: Autores.

Nessa localidade, após tratamento inicial, a genitora relatou melhora da distensão abdominal e melhora da coloração da urina, mas o quadro apresentava hipertermia e tosse produtiva por 4 dias, apresentando diurese espontânea em fralda e eliminação intestinal presente com coloração amarela, paciente choroso e pouco colaborativo, fontanela normotensa, presença de "nódulo" cefálico parietal (nega queda), ictérico, hidratado, tórax simétrico, abdome globoso, tenso, genitália hiperemiada.

Em seguida, a criança foi transferida para o Hospital Universitário Onofre Lopes (HUOL) em Natal-RN, onde foi internado, apresentando quadro de aumento do volume abdominal associado a cólicas evoluído, com icterícia contínua, colúria, 
hipocolia fecal, sem prurido há aproximadamente 3 semanas, mas apresentando tosse produtiva e rinorreia mucopurulenta, acompanhada de febre $\left(38^{\circ} \mathrm{C}\right)$. Foi observado, em exame, hiperbilirrubinemia mista com predomínio de bilirrubina direta, a elevação de transaminases (mais cinco vezes do limite superior de normalidade) e anemia normocítica e normocrômica, além de leucocitose discreta. Realizada a Ultrassonografia (USG) de abdome total, foi evidenciado fígado homogêneo discretamente aumentado de volume, não sendo visualizada vesícula biliar. Na Tomografia Computadorizada (TC), do abdômen e pelve verificou-se fígado de dimensões aumentadas e vesícula biliar hipodistendida, de avaliação prejudicada, notando-se líquido laminar perivesicular, concluindo hepatomegalia homogênea. Apresentando a persistência de máculas azuladas em dorso e membros.

O paciente foi acompanhado pelo cirurgião buco-maxilo-facial do Hospital Universitário Onofre Lopes, o qual verificou lesões em rebordo alveolar superior, inferior e palato duro, exofíticas formada por regiões eritroplásicas e leucoplásicas não removidas por raspagem com evolução de 1 mês (Figuras 6 e 7). A cirurgia de biopsia de tecidos moles da boca de caráter eletivo foi agenda, porém os exames laboratoriais do paciente apresentavam-se todos descompensados. Contudo, não foi possível a realização da biópsia tendo piora no quadro clínico do paciente que o levou a óbito.

Figura 6. Lesão em rebordo alveolar inferior.

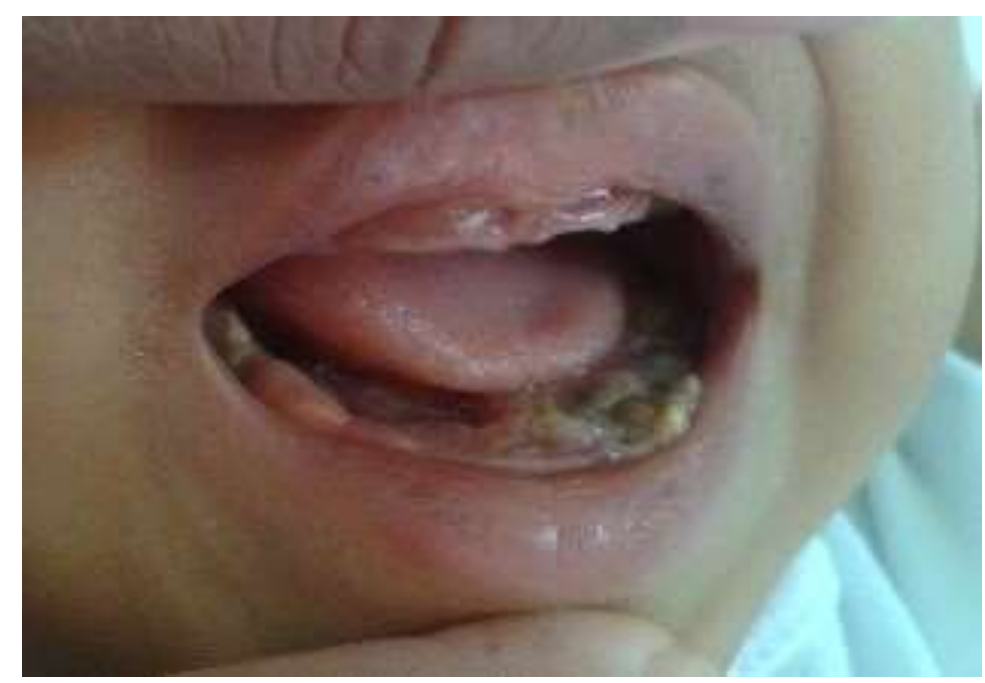

Fonte: Autores. 
Figura 7. Lesão em rebordo alveolar superior.

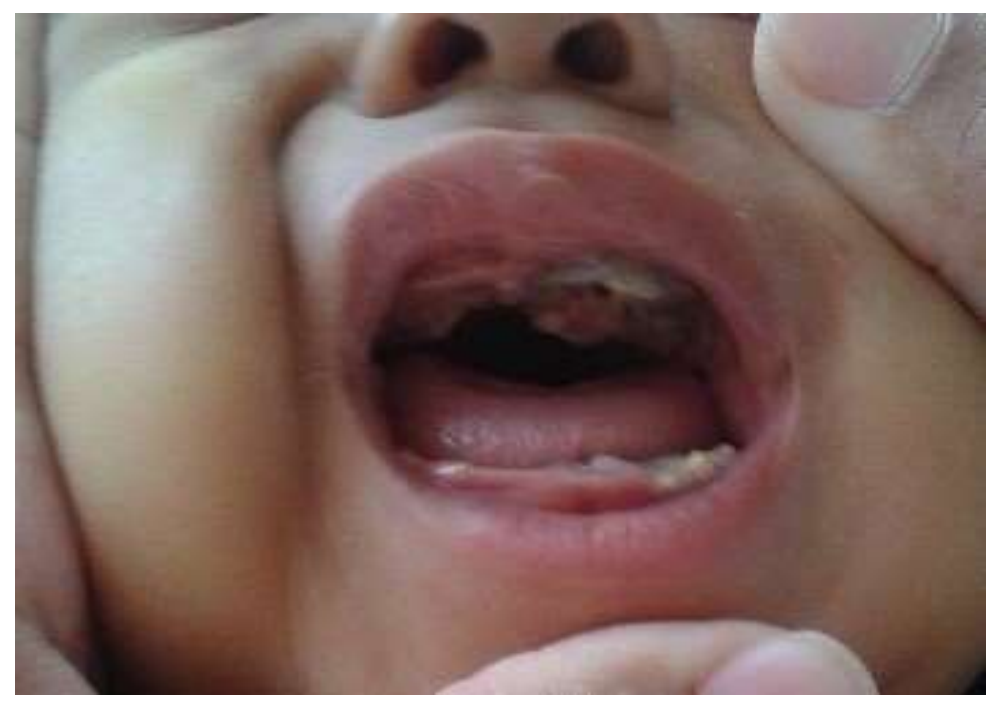

Fonte: Autores.

\section{Discussão}

A afecção apresentada possui um amplo espectro clínico, sendo possível identificar alterações solitárias ou múltiplas e benignas ou malignas (Aruna, et al., 2011). A doença acomete principalmente os ossos (80\% dos casos), sendo a calota craniana o sitio mais comumente afetado. Outros locais acometidos são a pele (33\%), a glândula hipófse (25\%), o fígado, o baço, a medula óssea e os pulmões (15\% cada), os linfonodos (5-10\%) e o sistema nervoso central, excluindo a hipófse (2-4\%) (Postini, et al., 2012) e (Haupt, et al., 2013).

A tomografia computadorizada (TC) é útil para determinar ruptura cortical e avaliação da destruição óssea. No crânio, as lesões são redondas e osteolíticas com bordas e aparência "perfurada" (Kilborn, et al., 2003). Em exame de TC em caso relatado por Kapoor, et al. (2015), mostrou múltiplas lesões osteolíticas nas áreas parietais do crânio bilateralmente. No estudo aqui descrito, em exame de tomografia computadorizada cranioencefálico, foi observado também falhas ósseas parietais circunferenciais sendo a histiocitose considerada como a principal hipótese diagnóstica, conforme laudo realizado, neste paciente.

O acometimento cutâneo manifesta-se na maioria dos pacientes como pápulas róseas, amareladas ou da cor da pele normal, variando de um a dois milímetros, pústulas e/ou vesículas no couro cabeludo e áreas flexurais do pescoço, axila e períneo, e no tronco. As lesões tendem a coalescer e tornar-se mais firmes. Escamas, erosões, ulcerações e crostas, com infecção secundária, e o surgimento de petéquias e púrpuras são comuns. Em alguns casos ocorrem nódulos, que eventualmente ulceram. Pode acometer o nariz e a região palmoplantar (Goodman \& Barret, 2003) e (Vieira, Guedes \& Azulay (2004). Esses achados corroboram com os aqui encontrados, uma vez que foi observado "nódulo" cefálico parietal (mãe nega queda), com manifestações em pele, como, máculas azuladas em dorso e membros e genitália hiperemiada.

As apresentações clínicas da LCH se confundem com diversas alterações, podendo fazer diagnóstico diferencial, das lesões em boca, com doença periodontal, malignidades como carcinoma epidermoide ou linfoma, bem como lesões granulomatosas ou ulcerativas características de infecções fúngicas, dificultando o diagnóstico, especialmente quando há acometimento de múltiplos órgãos (Pereda, et al., 2009). Faz-se necessária, portanto, uma profunda investigação em lesões que apresentem persistência após tratamento. Na cavidade oral, geralmente se apresenta como ulceração da mucosa associada a lesões ósseas subjacentes (Murray, Dean \& Slater, 2011). Comparando as evidências com o quadro clínico do presente estudo, pode-se perceber compatibilidade nas informações. Conforme relatado, na evolução em prontuário pelo Cirurgião 
Bucomaxilofacial da HUOL, foram observadas lesões em rebordo alveolar inferior, superior e palato duro, exofiticas formada por regiões eritroplásicas e leucoplásica não removida durante a raspagem. Mas, o grau de envolvimento sistêmico do paciente e a progressão rápida de doença não permitiram a realização do exame histopatológico das lesões orais.

O diagnóstico definitivo de LCH faz-se conjugando aspectos clínicos e achados histológicos e imuno-histoquímicos. A doença compartilha os mesmos aspectos histológicos, em todas as suas formas clínicas, os quais se caracterizam por proliferação das células de Langerhans, associada a infiltrado de polimorfonucleares, eosinófilos, neutrófilos, histiócitos e linfócitos, dependendo da duração da lesão. (Magno, et al., 2007).

Em um estudo de caso da LCH, a icterícia foi descrita raramente. Contudo, a LCH pode-se apresentar com características mais precoces de disfunção hepática; uma vez que a LCH infiltrativa têm uma afinidade por ductos biliares, causando colestase e aumento da GGT, ALP e bilirrubina (Liu, et al., 2012) Nos exames médico-clínicos do paciente estudado e nos seus exames laboratoriais, foi relatado, em prontuário, distensão abdominal, icterícia e hiperbilirrubinemia mista.

A causa da patologia hepática na LCH é devido aos efeitos diretos ou indiretos das células de Langerhans. Os efeitos indiretos são reversíveis e ocorrem devido à ativação de macrófagos em nosso corpo, levando a hepatomegalia, a esplenomegalia e a hipoalbuminemia. Contudo, as células de langerhans estão ausentes na biópsia hepática (Gey, et al., 2004). Em caso de direta envolvimento do fígado; existem dois tipos de patologia hepática relatada na biópsia. A primeira é uma infiltração de trechos do portal, sem células de Langerhans; e o segundo é caracterizado pela dominação das células de Langerhans nos tratos portais e ductos biliares (Guthery \& Heubi, 2001). Em investigações laboratoriais, a categoria de envolvimento direto é categorizado por colestase, devido ao dano a grandes ou médios ductos biliares. A progressão da doença é crônica e leva a o desenvolvimento de colangite esclerosante e, posteriormente, cirrose (Kapoor, et al., 2015). No caso clínico apresentado, o diagnóstico anátomo-patológico do Serviço de Verificação de Óbito - SVO-RN foi de Atresia de Vias Biliares Congênita e Cirrose Biliar Secundária.

Este trabalho teve como principal limitação a não realização da biópsia das lesões orais, devido ao agravamento do quadro geral do paciente e ao óbito. Contudo, o quadro clínico, os exames complementares laboratoriais e os de imagens foram compatíveis com o diagnóstico de Histiocitose das Células de Langehans.

A partir do caso clínico, aqui apresentado, não é possível realizar a inferência estatística, por não possuir representatitividade populacional. Além disso, não possibilita conclusões precisas sobre a associação da LCH com lesões de cavidade oral. No entanto tem sua importância, por se tratar de uma doença rara e, portanto, servir como base para se conhecer mais profundamente as caraterísticas da patologia estudada, assim como abrir a discussão sobre a importância do olhar clínico do profissional, independente do local de atuação, para diagnosticar precocemente, oportunizando um tratamento adequado.

Faz-se necessário salientar também que o cirurgião-dentista foi o primeiro profissional a ser procurado pela mãe da criança, uma vez que as lesões bucais foram os achados clínicos iniciais, o que destaca o papel desse profissional em relação a necessidade de um amplo conhecimento técnico e a responsabilização pelo seu paciente. Além disso, toda a condução do caso foi realizada por uma equipe multiprofissional, corroborando com o pensamento sobre a indivisibilidade do ser humano e o perfil profissional exigido na contemporaneidade, pautado na atenção interprofissional.

\section{Conclusão}

A LCH pode se apresentar de várias maneiras e, devido à sua natureza infiltrativa, pode envolver a pele, os gânglios, o pulmão, o fígado e a cavidade bucal. As lesões bucais são muitas vezes as únicas ou principais manifestações de determinadas doenças e que o seu diagnóstico precoce contribui positivamente para o tratamento. A LCH, por ser uma doença multissistêmica e de rápida progressão, requer atenção do cirurgião-dentista na realização da anamnese, exame extraoral e intraoral, confrontando achados clínicos em cavidade oral com quadro clínico observado, para possíveis diagnósticos precoces. 
Há necessidade de uma efetiva atuação da equipe multiprofissional para pacientes comprometidos com doenças sistêmicas, para estratégia conjunta de intervenção e de uma rede de atenção que possibilite o acesso do paciente a todos os níveis de densidade tecnológica, com agilidade para atender suas necessidades e integralidade da assistência.

\section{Referências}

Anniballi, S., Cristalli, M. P., Solidane, M., Ciavarella, D., La Monaca, G., Suriano, M. M., Lo Muzio, L. \& Lo Russo, L. (2009). Langerhans cell histiocytosis: oral/periodontal involvement in adult patients. Oral Dis., 15: 596-601

Aricò, M., Clementi, R., Caselli, D. \& Danesino, C. (2003). Histiocyte disorders. Hematol J. 4(3):171-9.

Aruna, D., Pushpalatha, G., Galgali, S. \& Prashanthy. (2011). Langerhans cell histiocytosis. J Indian Soc Periodontol., 15(3): 276-279

Fistarol S., Itin, P., Häusermann, P., Oberholzer, M., Raineri, I., Lambrecht, T. \& Lindenmüller, I. H. (2009). Unifocal Lang erhans cell histiocytosis of the oral mucosa. J Dtsch Dermatol Ges. 7: 620 e 622.

Gey, T., Bergoin, C., Paupard, T., Cazals-Hatem, D. \& Xuan, K. H. (2004). Langerhans cell histiocytosis and sclerosing cholangitis in adults. Rev Mal Respir. 21:997-1000.

Goodman, W. T \& Barret, T. L. (2003) Histiocytoses. In: Bolognia, J. L., Jorizzo, J. L. \& Rapini, R. P., editors. Dermatology. Philadelfia: Mosby, 1429-33

Guthery, S. L. \& Heubi, J. E. (2001). Liver involvement in childhood histiocytic syndromes. Current Opinion in Gastroenterology. 17:474-78.

Haupt, R., Minkov, M., Astigarraga, I., Shäfer, E., Nanduri, V., Jubran, R., Egeler, R. M., Janka, G., Micic, D., Rodrigues-Galindo, C., Gool, S. V., Visser, J., Weitzman, S. \& Donadieu, J. (2013). Langerhans cell histiocytosis (LCH): guidelines for diagnosis, clinical work-up, and treatment for patients till the age of 18 years. Pediatr Blood Cancer. 60(2):175-84.

Kapoor, R., Loizedes, A. M., Sascdeva, S. \& Paul, P. (2015). Disseminated Langerhans Cell Histiocytosis Presenting as Cholestatic Jaundice. Journal of Clinical and Diagnostic Research. 9(2): SD03-SD05.

Kilborn, T. N., The, J. \& Goodman, T. R. (2003). Paediatric Manifestations of Langerhans Cell Histiocytosis: a Review of the Clinical and Radiological Findings. Clinical Radiology. 58, 269-278.

Liu, D. G., Zhang, Y. \& Li, F. (2012). Multisystem Langerhans cell histiocytosis with liver dysfunction as the first presentation: A case report. Oncol Lett., 3(2):391-94. Epub 2011 Oct 26.

Magno, J. C. C., D’Almeida, D. G., Magalhães, V. J. P., Araújo, M. L., Miranda, C. B. \& Nagel, J. (2007). Histiocitose de Células de Langerhans em Margem Anal: Relato de Caso e Revisão da Literatura. Rev Bras Coloproct. 27:83-8.

Murray, M., Dean, J. \& Slater, L. (2011). Multifocal oral Langerhans cell histiocytosis. J Oral Maxillofac Surg. 2011,69:2585-91.

Neville, Brad W. (2016). Patologia Oral e Maxilofacial. (4a ed.), Elsevier, 824p.

Pereda-Martínez-Madrigal, C., Rodríguez-Guerrero, V., Moya-Guisado, B. \& García-Meniz, C. (2009). Langerhans cell histiocytosis: literature review and descriptive analysis of oral manifestations. Med Oral Patol Oral Cir Bucal. 2009, 4:222-8.

Postini, A. M., Prever, A. B., Pagano, M., Rivetti, E., Berger, M., Asaftei, S. D., Barat, V., Andreacchio, A. \& Fagioli F. (2012). Langerhans cell histiocytosis: 40 years' experience. J Pediatr Hematol Oncol. 34(5):353-8

Ribeiro, B. B., Guerra, L. M., Galhardi, W. M. P. \& Cortellazzi, K. L. (2012). Importância do reconhecimento das manifestações bucais de doenças e de condições sistêmicas pelos profissionais de saúde com atribuição de diagnóstico. Odonto. 20(39): 61-70.

Savasan, Süreyya. (2006). An enigmatic disease: childhood Langerhans cell histiocytosis in 2005. Int J Dermatol. $45,182-8$.

Schmidt, S., Eich, G., Hanquinet, S., Tschäppeler, H. Waibel, P. \& Gudinchet, F. (2004). Extraosseous involvement of Langerhans' cell histiocytosis in children. Pediatr Radiol. 34:313-321.

Vieira, A. G., Guedes, L. S. \& Azulay, D. R. (2004). Histiocitoses. In: Azulay, R. D., \& Azulay, D. R, editors. Dermatologia. 3 ed. Rio de Janeiro: Guanabara Koogan, p.355-6. 